\title{
Ingestion and elimination of anthropogenic fibres and microplastic fragments by the European anchovy (Engraulis encrasicolus) of the NW Mediterranean Sea
}

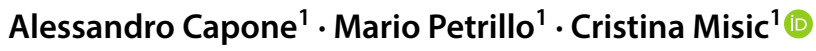

Received: 27 March 2020 / Accepted: 29 September 2020 / Published online: 16 October 2020

(c) The Author(s) 2020

\begin{abstract}
This study analysed the anthropogenic microparticles in the stomach content of the European anchovy (Engraulis encrasicolus) in the Ligurian Sea (NW Mediterranean). The results showed that $30-40 \%$ of the anchovies had ingested anthropogenic microparticles (on average, $0.34 \pm 0.29$ fibres ind ${ }^{-1}$ and $0.12 \pm 0.12$ fragments ind $^{-1}$ ). The fibres were probably ingested via filtration, and were significantly correlated with the gut fullness. Fibres were mostly dark, but the presence of other colours was frequent, indicating a general lack of selectivity. Plastic fragments composed of polyethylene and polypropylene were prevalently transparent, suggesting active predation, especially for larger fragments resembling zooplankton. No significant differences were recorded for the frequency of fish containing particles among females, males, and undetermined individuals. The presence of, generally, only one anthropogenic item per fish, as observed for $95.8 \%$ of fish containing microparticles, indicated that the permanence of these particles in the stomachs was short, likely no more than 1 day, although it could also depend on low environmental concentrations. The evaluation of the intestinal lumen indicated that a portion of the plastic fragments found in the stomach could not be ejected. Hard fragments that were larger than the intestinal lumen could be held for longer times, but probably regurgitation, fragmentation, and embedding in a biological matrix may facilitate their quick elimination. It is pivotal to understand the processes that regulate the abundance and the residential time of anthropogenic particles in commercial organisms captured for human nutrition, given the potential biomagnification of toxic substances carried by ingested particles.
\end{abstract}

\section{Introduction}

Anthropogenic materials are distributed in all the oceans and seas, playing destructive roles in the ecosystem. Toxicity, gas exchange limitations, and mechanical forcing on organisms are related to the presence of anthropogenic materials, and, in recent years, plastic has gained a leading position among these threats to the environment (Teuten et al. 2009; Deudero and Alomar 2015; Jovanović 2017). More recently, natural and synthetic textile fibres have become a matter of concern. As both have been found to sorb chemical

Responsible Editor: S. Hamilton.

Reviewed by undisclosed experts.

Cristina Misic

cristina.misic@unige.it

1 Department of Earth, Environment and Life Sciences, University of Genova, Corso Europa 26, 16132 Genova, Italy pollutants and potentially block feeding appendages or the passage of food, they can exert on the organisms the same deleterious effects of plastic fibres (Lusher et al. 2013; Ladewig et al. 2015; Remy et al. 2015).

Anthropogenic materials have been reported to be ingested by organisms (Anastasopoulou et al. 2013; Choy and Drazen 2013; Deudero and Alomar 2015; Romeo et al. 2015). Ingestion may occur accidentally and/or deliberately (Davison and Asch 2011; Boerger et al. 2010). Despite fish have a gustatory system that allows them to separate food from inedible items (Lamb 2001), the presence of anthropogenic microparticles (particle dimension ranging from $1 \mu \mathrm{m}$ to $5 \mathrm{~mm}$, Barnes et al. 2009) in their stomachs suggest that this ability is somehow impeded; for instance, it could be due to the co-occurrence of microparticles and food that masks the inedibility of some microparticles (Ory et al. 2018).

Analyses of the stomach contents of benthic fishes (Anastasopoulou et al. 2013; Neves et al. 2015; Battaglia et al. 2016; Bellas et al. 2016) and commercial pelagic fishes 
(Nadal et al. 2016; Compa et al. 2018) have shown a variable degree of contamination.

The ingested microparticles may have different shapes and colours. In the western Mediterranean, Rios-Fuster et al. (2019) found in four fish species (including pelagic fishes such as sardine and anchovy) a dominance of fibres (over 90\%) among anthropogenic particles, of which ca. $90 \%$ were microparticles (maximum size of $5 \mathrm{~mm}$ ). Dark colours such as blue and black dominated over transparent ones (72\% and $12 \%$, respectively), although other colours were also observed. In the Portuguese Atlantic coastal water, Neves et al. (2015) found a dominance of fibres in the stomach content of several fish species, similar to what Lusher et al. (2013) found in the English Channel and Rochman et al. (2015) found in Californian fishes. Wright et al. (2013) and Claessens et al. (2011) reported that ca. $60 \%$ of microparticles in the environment (such as sediment and water) was synthetic fibres.

Recent studies highlight that there is no correlation between the number of ingested particles and the trophic level of the species (Güven et al. 2017), indicating that occurrence of particles in the gastrointestinal tract of fish is transitory (Jovanović 2017). Nevertheless, anthropogenic particles may cause severe mechanical damage in the gastrointestinal tract of organisms, such as blocking the digestive tract or decreasing the energy uptake and leading to starvation (Cedervall et al. 2012; Nadal et al. 2016; Jovanović 2017). Moderate to pronounced alterations of the distal intestinal epithelium have been observed in fish, depending on exposure time to anthropogenic particles (Pedà et al. 2016).

Pollutants that are first adsorbed by the particles in the seawater or the chemical additives of the particle itself can be transferred to higher trophic levels. These substances are released in the fish gut and permanently assimilated by the organism (Oliveira et al. 2013; Koelmans 2015; Batel et al. 2016). The transfer of pollutants from the anthropogenic particles to the organism and the potential translocation to liver or hemolymph of nanoparticles (less than $1 \mu \mathrm{m}$ in dimension, Cole and Galloway 2015) and microparticles (conventionally between $1 \mu \mathrm{m}$ and $5 \mathrm{~mm}$, Arthur et al. (2009)) depends on the time the particle remains in the digestive tract (Pedá et al. 2016; Jovanović 2017).

Given the toxic effect and the potential biomagnification of harmful substances carried inside the organisms by anthropogenic particle ingestion, more studies are needed for the determination of particle abundance in the stomach and the residential time of these particles in the gastrointestinal tract of commercial organisms captured for human nutrition (Tanaka and Takada 2016; Jovanović 2017). The current scientific literature points to a contamination of internal organs and liquids; less is known about contamination of the muscle content. Nevertheless, we cannot ignore the possibility of pollutant translocation in parts of the fishes that are generally eaten by humans, although often the whole organism is ingested by human consumers (Tanaka and Takada 2016).

The European anchovy Engraulis encrasicolus (Linnaeus 1758) is an edible fish that is highly exploited in the Ligurian Sea (north-western Mediterranean Sea). The high level of contamination in the Mediterranean Sea by microplastics and other anthropogenic particles (Deudero and Alomar 2015; van Sebille et al. 2015) indicates that this pelagic fish may be involved in microparticle ingestion and transfer of toxic compounds to higher consumers (such as humans).

The morphological characteristics of the Mediterranean Sea cause limited water exchange with the Atlantic Ocean; added to this, the high human population density and activity along the coasts make anthropogenic materials dispersion at sea a critical issue (Eriksen et al. 2014; Cózar et al. 2014; Suaria et al. 2016). About $80 \%$ of these materials are made of plastic, with a dominance of small-sized plastic (Fossi et al. 2017). In the north-western Mediterranean, previous studies have highlighted the presence of a surface-layer accumulation site for microplastic in the eastern area of the Ligurian Sea (Fossi et al., 2012). This area was also confirmed as a 'hot spot' for microplastics by Collignon et al. (2012), due to the peculiar hydrodynamic and wind characteristics. High concentrations of microplastic were also found in the northern Tyrrhenian Sea (Baini et al. 2018), whose water flows into the eastern Ligurian Sea at a rate dependant on meteo-climatic conditions (Astraldi et al. 1999).

The present paper determines the presence of anthropogenic microparticles in the stomach content of the anchovy, focusing on characteristics of the microparticles such as typology, dimension, colour, and, when possible, composition during the spring of four consecutive years (2011-2014). To study the respective influence of microparticles and morphological features of anchovies, dimension, Fulton's condition factor, and sexual maturity were determined. In particular, the lumen dimension of the intestine was measured in several specimens, to gather information on the possibility for the anchovies to expel anthropogenic microparticles.

\section{Materials and methods}

\section{Study area}

The Ligurian Sea is a deep sea with a limited continental shelf. The main current flows northerly, originating from the mixing of waters of the Tyrrhenian Sea and of the current that flows along the western coast of Corsica Island. When the main current reaches the Ligurian coast, it turns to the West, conditioned by the shape of the land. Local upwelling occurs due to the presence of marine canyons (Astraldi et al. 
1999; Bakun and Agostini, 2001). Cold winter winds allow an increased transport of inorganic nutrients to the surface layer, enhancing primary production (Lacroix et al. 2001) and diatom blooms (Gómez and Gorsky 2003).

The Ligurian Sea shows oligo-mesotrophic features. The spring phytoplankton biomass accumulation peaks in March (Marty et al. 2002; Estrada and Vaqué 2014), allowing the consequent increase of zooplankton biomass and community complexity, with a dominance of Copepods (SiokouFrangou et al. 2010).

\section{Study object (E. encrasicolus)}

The anchovy E. encrasicolus is a small pelagic fish, largely captured in the Ligurian Sea for human consumption. Depending on the climatic and wind-wave conditions, the fishing season starts in February and ends in October. In the Ligurian Sea, the main fishing gear is the purse seine. $E$. encrasicolus has a relatively short life cycle and shows fast growth during the early stages (Bonanno et al. 2016; Compa et al. 2018). The branchial apparatus of the juveniles and adults has a series of gill arches, which form a filtering net constituted by gill-rakers that increase in complexity with the growth of the fish. These structures allow the anchovy to express different feeding responses to food availability; they use: particulate-feeding on large zooplankton and filterfeeding on diatoms and small zooplankton (Van der Lingen, 1998). The choice of the feeding response depends, substantially, on the prey presence, and it is not influenced by environmental features such as light (Bulgakova 1993; James and Findlay 1989). More recent studies performed in the eastern Mediterranean Sea highlighted that anchovies show the fastest growth rates during spring and a slower growth during autumn, in accordance with the variation of zooplankton prey availability (Politikos et al. 2011). Van der Lingen et al. (2006), in a comparative study between anchovy and sardine trophodynamics, highlighted that the branchial apparatus of anchovy was relatively coarse, meaning that anchovies feed predominantly by particulate-feeding and have more efficient clearance rates than sardine for prey larger than $580 \mu \mathrm{m}$. Other metabolic abilities, such as an efficient assimilation of nitrogen from zooplankton and an excretion rate lower than $50 \%$ of the ingested nitrogen, suggest that anchovies maximise their scope for growth on mesozooplankton. Nevertheless, anchovies can easily switch between the two feeding modes to maximise the energy intake; they can be opportunistic in relation to the changing environmental characteristics (Borme et al. 2009).

\section{Sampling}

Samples were collected during commercial fishing activities using the purse seine fishing gear (net mesh size of $14 \mathrm{~mm}$ ).
Sampling was performed during the night, from 0000 to $0430 \mathrm{~h}$. The sampling area was in the eastern part of the Liguria (Fig. 1), approximately from the Portofino promontory to the shelf area between Liguria and Tuscany. The bottom depth ranged between 55 and $120 \mathrm{~m}$.

The spring months, from March to May, of 2011 to 2014 were studied, except in 2014 when only March and April were sampled. Samples were collected a minimum of one to a maximum of five sampling dates for each month, depending on the wind-wave conditions and fishers activity, for a total of 32 sampling dates. For each sampling, 15.6 \pm 4.3 individuals were randomly isolated.

\section{Laboratory analyses}

The fishers provided the samples within $5 \mathrm{~h}$ after capture. Fish were stored in a clean cooler box, and brought to the laboratory within $2 \mathrm{~h}$.

The fish were measured to the nearest $0.5 \mathrm{~cm}$ (total length) and weighed (wet weight, $\pm 0.1 \mathrm{~g}$ with a Kern PCB electronic balance). Fulton's condition factor (K) was calculated using the following formula (Froese 2006):

$\mathrm{K}=100 \times\left(\right.$ weight $/$ total length $\left.^{3}\right)$.

The gut (oesophagus, stomach, and intestine) was carefully removed and fixed in 70\% ethanol. A total of 100 intestinal tracts, isolated in anchovies of different maturities,

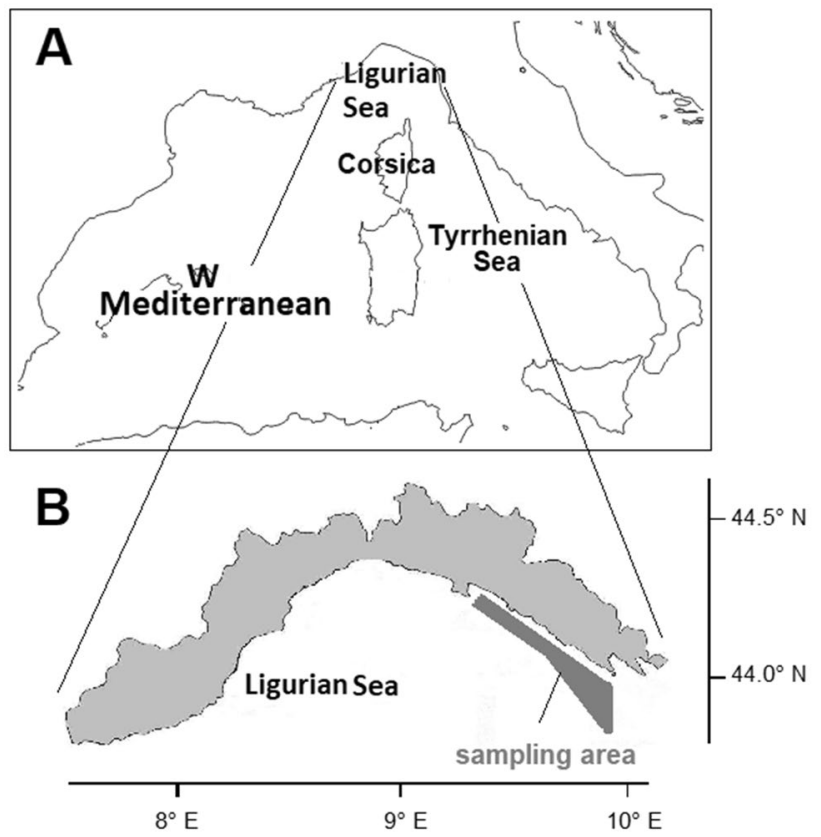

Fig. 1 Sampling area. a Position of the study area (eastern Ligurian Sea) in the W Mediterranean. b Sampling zone, the anchovies were captured in the dark grey area in the eastern part of the Ligurian Sea 
length, weight, and sex, were analysed for their diameter with a Leica Z16 APO stereomicroscope equipped with Leica application suite software.

Fish stomachs were weighed to the nearest $0.1 \mathrm{mg}$ (wet weight, Mettler Toledo electronic balance), placed on a petri dish, and carefully cut longitudinally with a micro-dissecting lancet. The stomach contents were transferred to a petri dish, carefully washing the stomach walls with $70 \%$ ethanol. The empty stomach was weighed again to calculate the net stomach-content weight.

Stomach contents were examined under the dissecting microscope (Zeiss Stemi DV4) at $8 \times$ to $32 \times$ magnification to differentiate fragments and fibres from other non-anthropogenic particles such as zooplanktonic prey, following previous protocols (Lusher et al. 2013; Nadal et al. 2016). To avoid contamination, operators wore always a white $100 \%$ cotton lab coat, and all the tools were washed with ethanol and checked before use. All anthropogenic microparticles were counted, and their type (fragments and fibres) and colour were recorded. Fragment dimensions were measured with a Leica Z16 APO stereomicroscope equipped with Leica Application Suite software. All fragments were analysed with transmission Fourier Transform Infrared (FT-IR) spectroscopy (4000-700 $\mathrm{cm}^{-1}$ PerkinElmer Spectrum 65) using commercial and custom-made spectral databases for microplastic identification. Using FT-IR, we discriminated natural (such as zooplankton fragments) and anthropogenic fragments (such as microplastics). The analyses on the fibres were not performed, due to the small dimension. Fibres were identified according to morphological characteristics and physical properties (e.g., response to physical stress, whether they were bendable or soft, and colour) as reported in Hidalgo-Ruz et al. (2012).

Gonads were removed to determine the sex of the specimens. After determination, the gonads were weighed to the nearest $0.1 \mathrm{mg}$ with a Mettler Toledo electronic balance (wet weight). The gonadosomatic index (GSI) was calculated as the percentage of the weight of the ovaries or testes with respect to the body weight of each fish (Cubillos and Claramunt 2009).

\section{Statistical analyses}

Univariate statistical analyses were performed with STATISTICA software. Pearson correlation was used to test the significance of the relationships among the trends of the different variables. In particular, the anchovy characteristics were related to the incidence (\%) of fish containing microparticles, and to the fibre and fragment content of the stomachs. We aimed at testing whether the dimensions (length and weight), the status (Fulton's condition factor), the sexual maturation (gonad weight and GSI), and the feeding activity (stomach-content weight) of anchovies were related to the ingestion of microparticles. A one-way ANOVA, followed by a Tukey's post hoc test, was used to verify the differences between samplings for the same variable. In particular, differences between years and months were tested.

Multivariate analysis was performed using Primer 6 and PERMANOVA $+\beta 3$ software, and Brodgar software (Brodgar 2.5.6 package, 2011, Highland Statistics Ltd.).

Anchovy characteristics and microparticle characteristics were analysed separately by distance-based permutational univariate analysis of variance (two-way PERMANOVA), with year and month nested in year as factors (Anderson et al. 2008).

Non-metric multi dimensional scaling analysis (nMDS) was applied separately on the data of anchovy characteristics and microparticle characteristics, previously normalised and resembled with Euclidean distances (Clarke and Gorley 2006).

Analysis of Redundance (RDA) was applied (Zuur et al. 2007). RDA investigates the influence exerted by the variation of one set of variables (explanatory variables) on the variation of another set of variables (response variables). An automated forward selection model was applied to test the order of importance of the explanatory variables. In particular, the "conditional effects" that show the increase in total sum of eigenvalues after including a new variable during the forward selection, were calculated. Finally, a permutation test was applied (number of permutations: 499) to test the null hypothesis that the explained variation is larger than a random contribution. The normalised data of the anchovy characteristics and microparticle characteristics were analysed separately. The two data sets were considered as response variables, while year and month as explanatory variables. The analysis was performed to test whether differences in the morphology, sexual maturation, and gut fullness of anchovies and in the microparticle characteristics were explained by years or months. A third RDA was performed using microparticle characteristics as response variables and anchovy characteristic as explanatory variables.

\section{Results}

\section{E. encrasicolus characteristics}

The entire data set, namely the average $\pm \mathrm{SD}$ of the variables for each sampling date, is reported in appendix-Table 1 . The nMDS plot (Fig. 2a) showed that the observations related to the different years were similar. In fact, the RDA (sum of all canonical eigenvalues: 0.32 , eigenvalue axis 1: 0.29 , axis 2: 0.03) showed that the anchovy characteristics were explained by months, but not by years (Table 1). This is in agreement with the PERMANOVA analysis (Table 2) 
Table 1 Results of the forward selection model applied for the three RDAs: conditional effects

\begin{tabular}{lllcc}
\hline Response variables & Explanatory variable & Increase & F-statistic & $P$ value \\
\hline Anchovy characteristics & Month & 0.28 & 11.67 & 0.002 \\
& Year & 0.04 & 1.59 & 0.186 \\
mps Characteristics & Year & 0.18 & 6.49 & 0.002 \\
& Month & 0.11 & 4.51 & 0.008 \\
mps Characteristics & Fulton's & 0.12 & 4.46 & 0.012 \\
& Stomach content & 0.11 & 3.53 & 0.044 \\
& Gonad weight & 0.02 & 0.91 & 0.386 \\
& Length & 0.01 & 0.45 & 0.626 \\
& Weight & 0.01 & 0.29 & 0.754 \\
& GSI & 0.01 & 0.18 & 0.860 \\
\hline
\end{tabular}

Increase increase in explained variation due to adding an extra explanatory variable
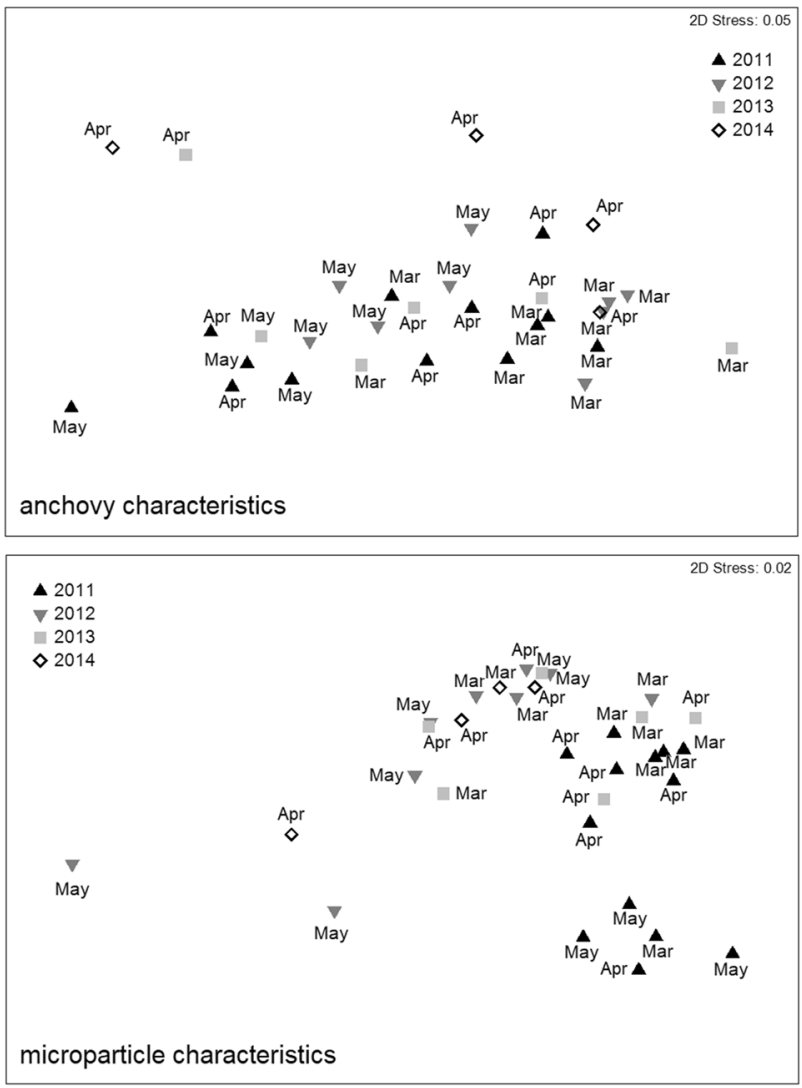

Fig. 2 nMDS plots for (a) anchovy characteristics, b microparticle characteristics

that showed a significant difference between months but not between years.

Total length and weight (Fig. 3a) increased from March to May every year. The longest and heaviest individuals have been observed in 2011, while 2012, on average, had the shortest and lightest, despite the differences were not significant. The Fulton's condition factor (K) (Fig. 3b) showed slightly higher values for $2011(0.65 \pm 0.03)$ than for the two following years (2012: $0.60 \pm 0.05 ; 2013: 0.63 \pm 0.03)$ and year 2011 was significantly higher than 2014 [0.57 \pm 0.02 , one-way ANOVA, F $(1.15)=7.153, P=0.017]$.

The stomach content (Fig. 3c) was generally highest in the last sampling dates of each year, namely May. April 2013 and April 2014 were anomalous; more than a half of the analysed fish had stomach content greater than $0.5 \mathrm{mg}$.

The gonad weight of the fish (Fig. 3c) was small in March, except for the first sampling of 2011 and the second sampling of 2013. Similarly, the GSI (Fig. 3d) increased to $3.0 \pm 0.7 \%$ in May 2011 and $2.6 \pm 1.1 \%$ in May 2013, while it only increased to $1.5 \pm 0.4 \%$ in 2012 . The small dimensions of the gonads prevented determination of the sex in many of these individuals. The undetermined individuals were abundant at the beginning of each sampling year (Fig. 3e), especially in $2011(79.3 \pm 35.6 \%)$. In 2012, there was a high number of undetermined individuals in March $(52.2 \pm 7.1 \%)$, April (85\%) and in the first sampling of May (47\%), in accordance with the small dimensions (length and weight) previously reported. In 2013, there was the lowest number

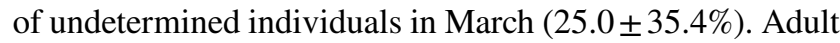
females and males contributed differently to the sample (on average females $30.8 \pm 20.4 \%$, males $38.6 \pm 18.7 \%$ ), but not significantly. The year with the higher female contribution was $2013(55.7 \pm 24.0 \%)$. The maximum contribution of males $(45.2 \pm 19.4 \%$ and $45.8 \pm 22.4 \%$, respectively) occurred in 2011 and 2014, respectively.

The diameter of the first (stomach-side) and last (anusside) tracts of the intestine in relation to fish length is shown in Fig. 3f. Increasing mean values of the lumen were observed, although the high variability of the results, as shown by the SD values, prevents significant differences among the lumen diameter. However, the anus-side lumen of the $9 \mathrm{~cm}$-long anchovies was significantly smaller than the anus-side lumen of anchovies ranging from 12 to $14.5 \mathrm{~cm}$ in length [one-way ANOVA, F $(1.78)=3.336$, $P=0.024]$, and the stomach-side lumen in the 9-cm-long anchovy was significantly smaller than the dimensions of 
Table 2 Results of the two-way PERMANOVA performed on the anchovy characteristics and microparticle characteristics

\begin{tabular}{llrlllll}
\hline & & Df & Sums of Sqs & Mean Sqs & F.Model & R2 & $\operatorname{Pr}(>$ F) \\
\hline Anchovy & Year & 3 & 55.31 & 18.436 & 1.4167 & 0.09459 & 0.267 \\
character- & Month (year) & 7 & 256.13 & 36.59 & 2.8118 & 0.43805 & 0.031 \\
istics & Residuals & 21 & 273.27 & 13.013 & 0.46736 & & \\
& Total & 31 & 584.71 & 1 & & & \\
Microparti- & Year & 3 & 1052.6 & 350.86 & 1.2656 & 0.11557 & 0.359 \\
cle charac- & Month (year) & 7 & 2233.3 & 319.04 & 1.1508 & 0.24521 & 0.340 \\
teristics & Residuals & 21 & 5821.8 & 277.23 & 0.63922 & & \\
& Total & 31 & 9107.7 & 1 & & & \\
\hline
\end{tabular}
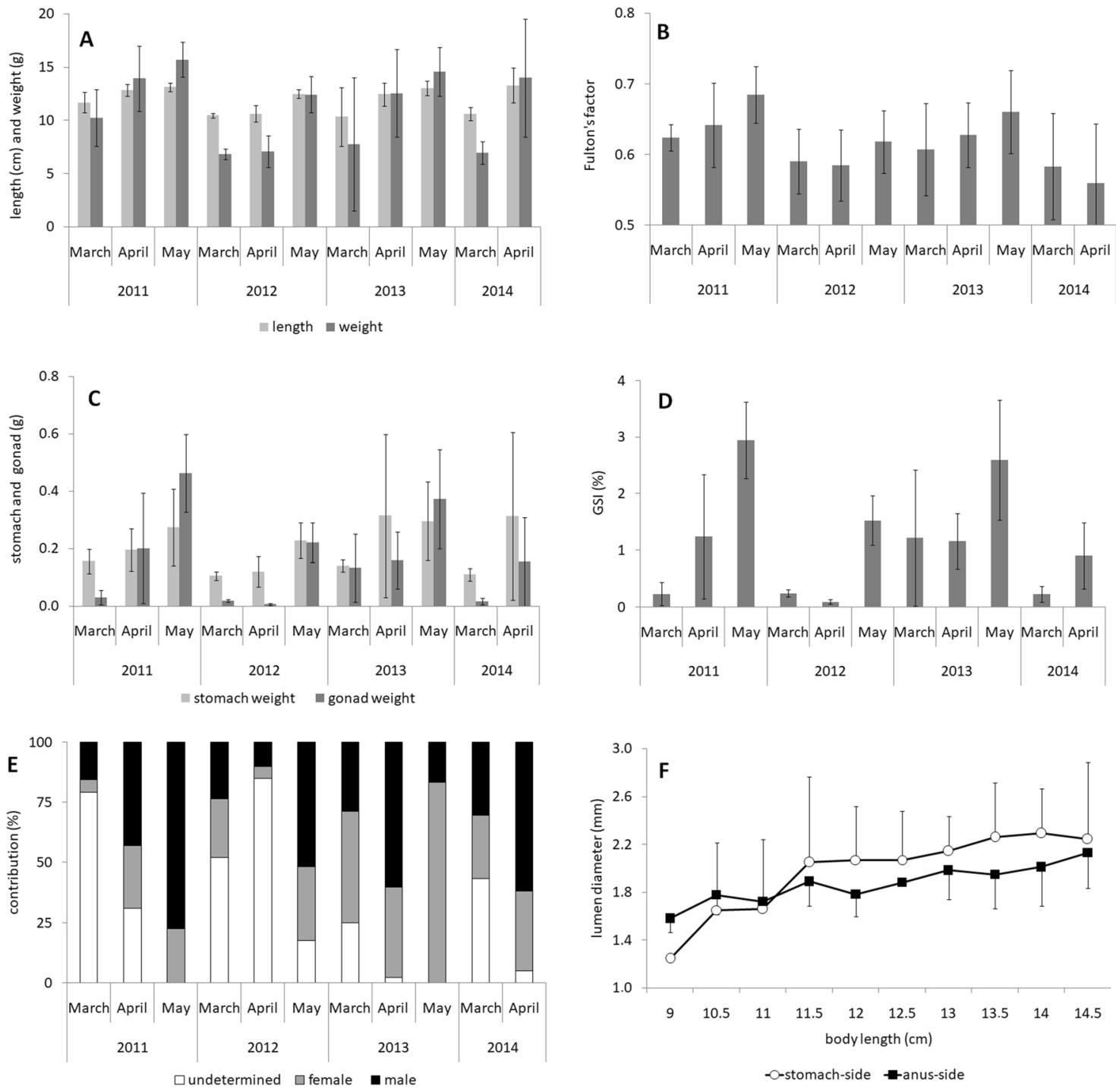

Fig. 3 Dimensional and reproductive features of the anchovy in 2011-2014. Averages \pm SD for each month for: a total length (length, $\mathrm{cm}$ ) and wet weight of the individuals (weight, g); b Fulton's condition index (Fulton's); $\mathbf{c}$ the wet weight of the stomach content (stomach, g) and gonad wet weight (gonad, g); d gonadosomatic index

(GSI, \%); e contribution (\%) of undetermined (undet.), female, and male individuals on the total number of fish; F) averages (mm) of the lumen of the intestine (stomach-side + SD and anus-side - SD) for size classes from 9.0 to $14.5 \mathrm{~cm}$ 
the longer anchovies (12-14.5 cm long) [one-way ANOVA, $\mathrm{F}(1.54)=4.193, P=0.009$ ]

\section{Microparticle abundance and typology in the individuals}

The entire dataset, namely the average \pm SD of the variables for each sampling date, is reported in appendix-Table 2 . PERMANOVA showed that the incidence of microparticles in the individuals and the number of fibres and fragments per individual were not significantly different between years and months (Table 2). However, in the nMDS plot (Fig. 2b), the observations of the year 2011 were often separated from the others. In addition, RDA (sum of all canonical eigenvalues: 0.29 , eigenvalue axis $1: 0.21$, axis $2: 0.08$ ) pointed to a role of both years and months in the variability of the particle characteristics (Table 1).

Generally, the incidence of fish containing microparticles increased during the season (Fig. 4a). Year 2013 was an exception, showing a decreasing trend. This trend affected the significance of the difference between months, as shown by PERMANOVA. For each year, the number of individuals containing microparticles ranged between $29 \pm 4 \%$ (2013) and $39 \pm 12 \%$ (2014), with an average of $34 \pm 4 \%$ across all years.

We observed a slightly higher incidence of microparticles for females $(39 \pm 23 \%)$ than for males $(36 \pm 19 \%)$ and undetermined specimens $(24 \pm 19 \%)$, but it was not significant due to the high variability (Fig. 4b).

The individuals containing anthropogenic materials showed generally only one microparticle each, although sometimes they contained 2 items ( $3.0 \%$ of the observations) or more than 2 items (1.2\%).

The averages of microparticle content in the stomach of anchovies (fibres and fragments per individual) are reported in Fig. 4c. The abundance of fibres was the lowest in 2011 $\left(0.15 \pm 0.03\right.$ fibres ind $\left.^{-1}\right)$ and increased in 2012 (reaching the maximum value of $1.17 \pm 0.41$ fibres ind $^{-1}$ and an average of $0.48 \pm 0.23$ fibres ind ${ }^{-1}$ ). The fibre abundance was significantly higher in 2012 than in 2011 [one-way ANOVA, F $(1.20)=17.973, P=0.001$ ], but it was similar for the years 2012, 2013, and 2014. This trend affected the significance of the difference between years, as shown by PERMANOVA. The abundance of fibres ranged between $0.31 \pm 0.06$ fibres ind $^{-1}$ and $0.48 \pm 0.06$ fibres ind $^{-1}$ in 2013 and 2014, respectively.

Fragments were more abundant in $2011(0.25 \pm 0.09$ fragments ind ${ }^{-1}$ ) in particular during May, which had the highest values recorded $\left(0.35 \pm 0.07\right.$ fragments ind $\left.{ }^{-1}\right)$, significantly higher than the other months [one-way ANOVA, $\mathrm{F}(1.11)=6.103, P=0.031]$. The values were below 0.1 fragments ind $^{-1}$ in the other years. In 2011, the fragment abundance was significantly higher than in 2012

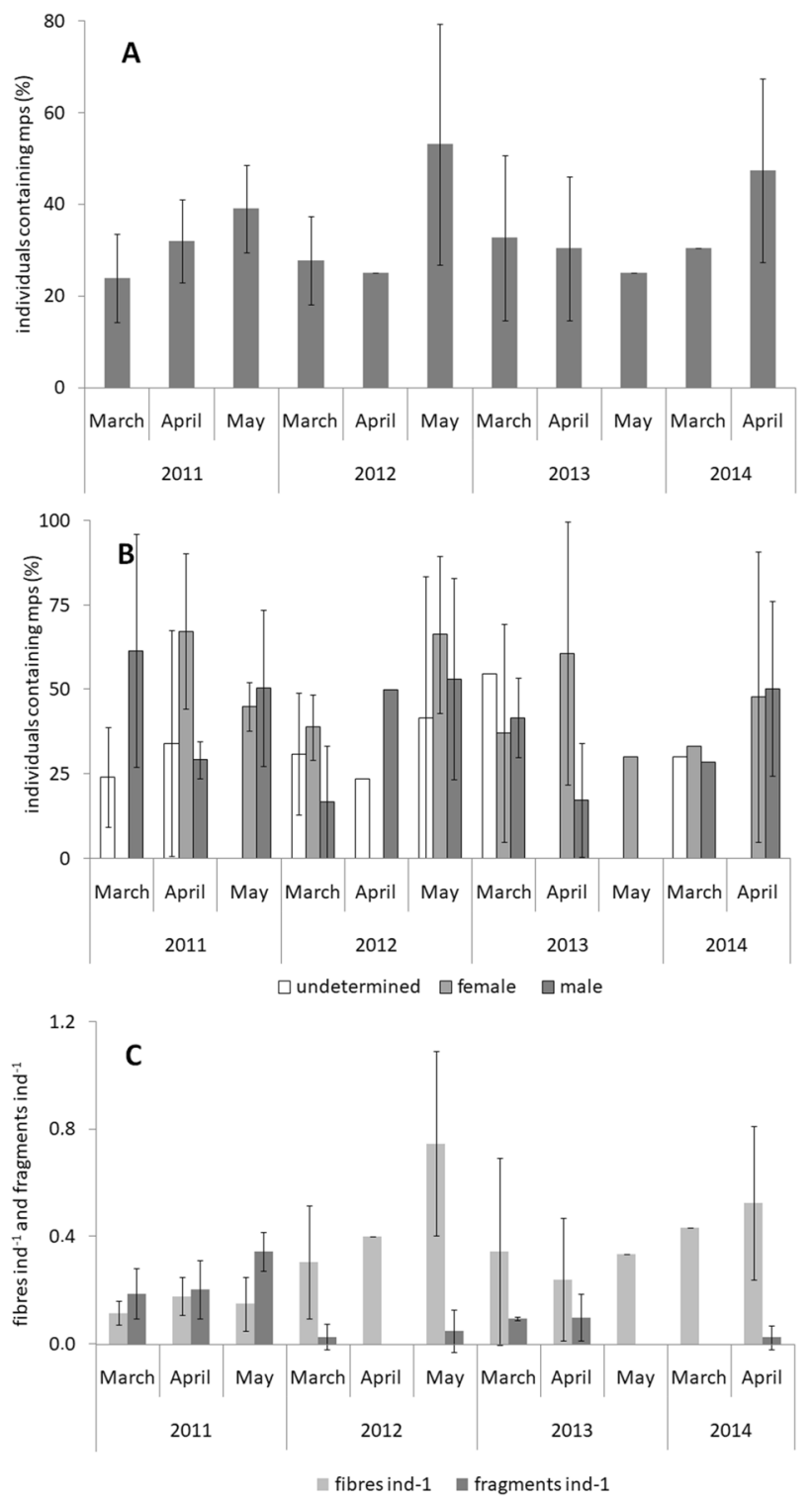

Fig. 4 Microparticles (mps) in the anchovies in 2011-2014. Averages $( \pm$ SD when available) for each month for: a the incidence of individuals containing $\mathrm{mps}(\%)$; $\mathbf{b}$ the incidence of undetermined individuals (undet.), females, and males containing microparticles (fibres and fragments) (\%); $\mathbf{c}$ the abundance of fibres and fragments per individual $\left(n\right.$ ind $\left.^{-1} \pm \mathrm{SD}\right)$

[one-way ANOVA, F $(1.20)=22.585, P<0.001], 2013$ $[\mathrm{F}(1.17)=9.128, P=0.008]$ and $2014[\mathrm{~F}(1.15)=13.658$, $P=0.002]$.

The RDA performed using the microparticle characteristics as response variables and the anchovy characteristics as explanatory variables (sum of all canonical eigenvalues: 0.27 , eigenvalue axis $1: 0.17$, axis $2: 0.10$ ) showed that the Fulton's condition factor and the weight of the stomach content had a role in the abundance and typology of microparticles in the individuals (Table 2). In fact, the fragment 
content per individual was positively correlated to the Fulton's condition index $(r=0.42, N=32, P<0.05)$ (Fig. 5). In addition, the fragment content per individual was linked to the reproductive maturation of anchovies; it was positively correlated to gonad weight $(r=0.38, N=32, P<0.05)$ and with the gonadosomatic index $(r=0.38, N=32, P<0.05)$. The stomach-content weight was positively correlated to the fibre number per individual $(r=0.37, N=32, P<0.05)$. The incidence of fish containing microparticles was related to the increase in dimension and feeding activity; it was positively correlated with anchovy weight $(r=0.36, N=32, P<0.05)$ and with the weight of the stomach content $(r=0.43, N=32$, $P<0.05)$.

In 2011, a higher number of plastic fragments were found (41) than in the other years (four in 2012, six in 2013, and one in 2014). The fragments from 2011, analysed with

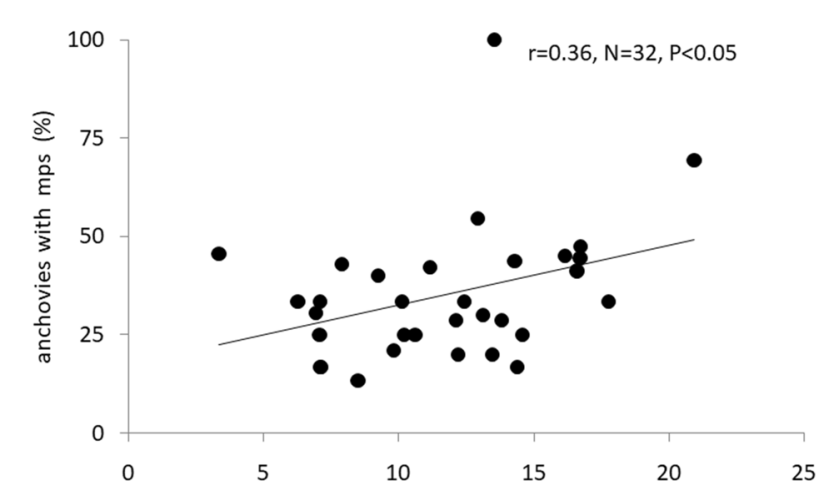

A
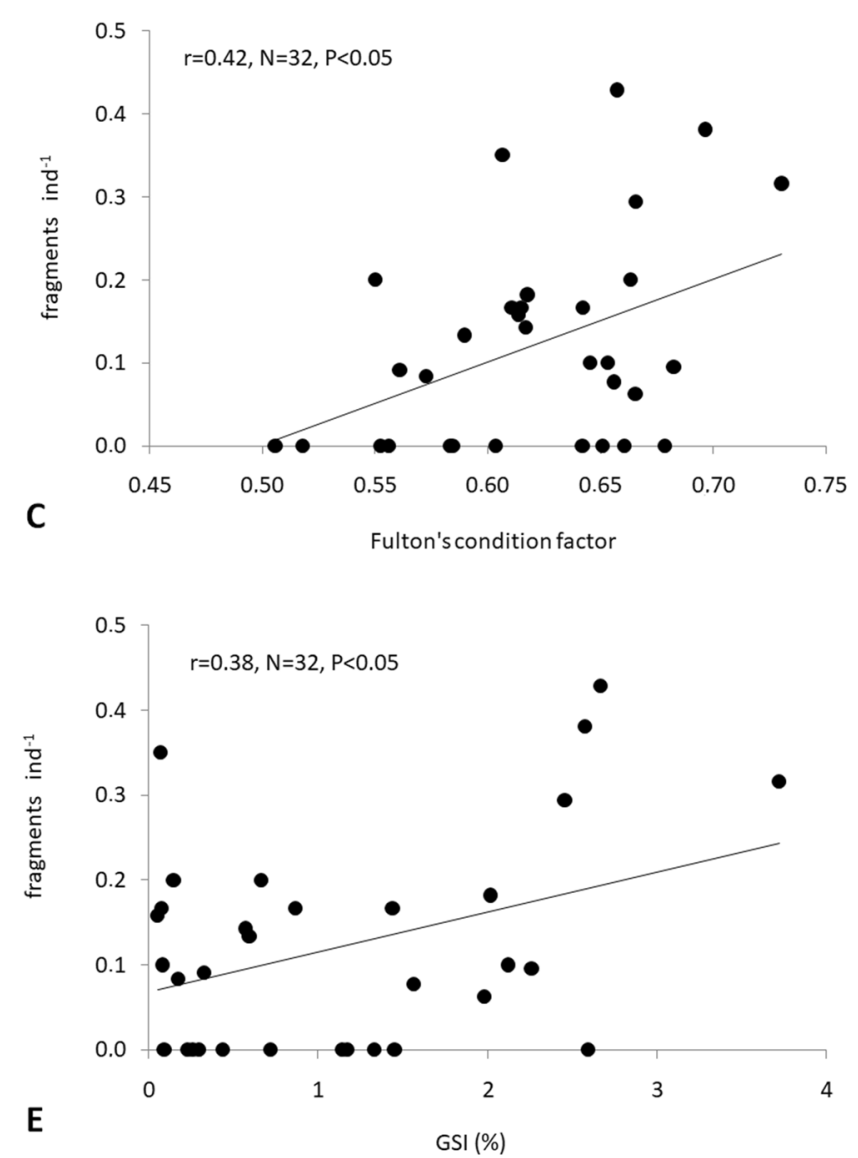
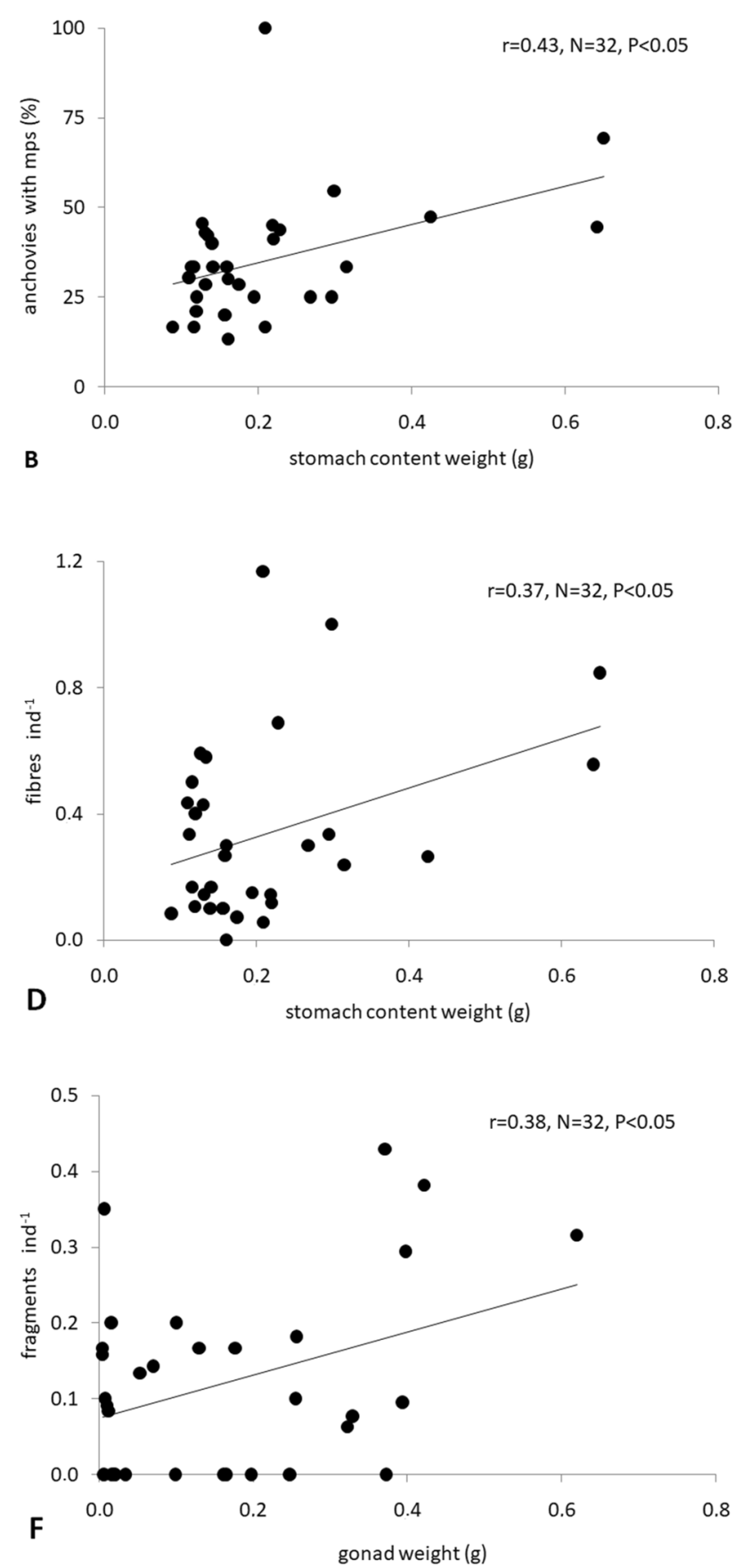

Fig. 5 Significant relationships among microparticles (mps) and anchovy characteristics. The correlation information (coefficient, number of observations and $P$ ) is provided for each graph 
FT-IR, show a dominance of polyethylene (PE) (total of 31 fragments, representing $71 \%$ of the total identified fragments in March, $87 \%$ in April and 73\% in May), against polypropylene (PP) (10 fragments) (Table 1). No other plastic types were found. The FT-IR analyses on the fragments of the other years confirmed the dominance of PE. Figure 6 shows photographs of representative fragments of typical shapes.

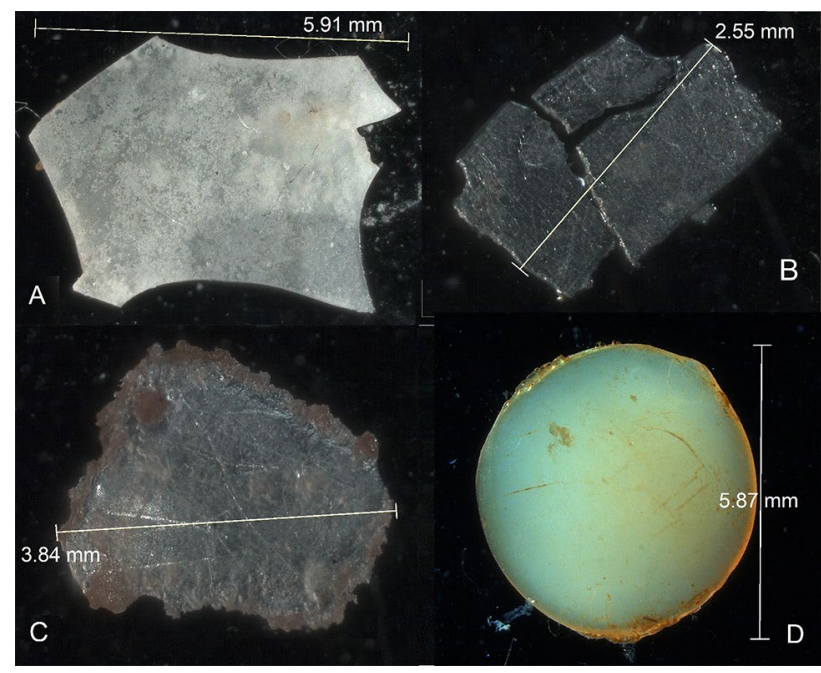

Fig. 6 Examples of fragments characterised by: a acute angles (polyethylene); $\mathbf{b}$ fragmentation of a single piece into three parts (polypropylene); $\mathbf{c}$ fragment with eroded sides (polyethylene); $\mathbf{d}$ the sphere of biological material containing a large polyethylene fibre
The plastic microparticles often had very acute angles and were hard (Fig. 6a). Sometimes, they showed acute angles (Fig. 6b), and their morphology suggested that they can be due to the breaking of a larger particle into pieces. Nevertheless, some pieces showed irregular, rough, and thin sides as a result of progressive degradation (Fig. 6c). The embedding of plastic items in a biological matrix (mainly lipidic) was observed only in three females longer than $14 \mathrm{~cm}$ and actively reproducing (one example, containing a fibre identified as low-density PE by FT-IR, is shown in Fig. 6d).

In 2011, the fragment dimensions ranged from 0.56 and $7.70 \mathrm{~mm}$ in length and 0.25 and $5.5 \mathrm{~mm}$ in width; the average values for each month are reported in Table 1. In 2011, a large part of the 41 identified microplastic fragments showed dimensions larger than the stomach-side tract (19 microparticles, $41 \%$ ) or the anus-side tract (23 microparticles, 56\%). This led to average values generally larger than the average lumen diameter calculated for the stomach-side and anusside of the intestine (Table 3). Hypothetically, if the intestine could increase its lumen by $50 \%$, some months (March and April) would still have fragments larger than the lumen. These fragments were made of PP. The same happened also in the other years, especially in March 2013, but it was limited to a low number of fragments (only 1 of 11) (Table 3).

The most represented colours of fibres (Fig. 7a, the entire data set is reported as appendix - Table 3) were dark (black and blue), ranging from $73 \pm 31 \%$ in 2012 to $80 \pm 34 \%$ in 2011 and $80 \pm 21 \%$ in 2013 . Nevertheless, coloured fibres
Table 3 Monthly averages of the fragment dimensions (length \pm sd and width \pm sd), composition ( $P E$ polyethylene, $P P$ polypropylene), and number of analysed fragments.

\begin{tabular}{|c|c|c|c|c|c|c|c|c|}
\hline Year & Month & Composition & Number & Length & Width & Mean fish length & $\begin{array}{l}\text { Larger } \\
\text { than } \\
\text { lumen }\end{array}$ & $\begin{array}{l}\text { Larger than } \\
\text { lumen*1.5 }\end{array}$ \\
\hline \multirow[t]{6}{*}{2011} & \multirow[t]{2}{*}{ March } & $\mathrm{PE}$ & 10 & $2.3 \pm 1.5$ & $1.0 \pm 0.8$ & \multirow[t]{2}{*}{$11.7 \pm 0.9$} & Yes & No \\
\hline & & PP & 4 & $5.0 \pm 2.8$ & $1.2 \pm 0.9$ & & Yes & Yes \\
\hline & \multirow[t]{2}{*}{ April } & $\mathrm{PE}$ & 13 & $2.7 \pm 1.9$ & $1.3 \pm 0.9$ & \multirow[t]{2}{*}{$12.8 \pm 0.6$} & Yes & No \\
\hline & & $\mathrm{PP}$ & 2 & $4.0 \pm 2.3$ & $2.2 \pm 2.5$ & & Yes & Yes \\
\hline & \multirow[t]{2}{*}{ May } & $\mathrm{PE}$ & 8 & $3.0 \pm 1.6$ & $2.1 \pm 1.6$ & \multirow[t]{2}{*}{$13.1 \pm 0.4$} & Yes & No \\
\hline & & $\mathrm{PP}$ & 4 & $3.0 \pm 0.9$ & $0.8 \pm 0.5$ & & Yes & No \\
\hline \multirow[t]{4}{*}{2012} & \multirow[t]{2}{*}{ March } & $\mathrm{PE}$ & 1 & 1.6 & 1.2 & \multirow[t]{2}{*}{$10.5 \pm 0.2$} & No & No \\
\hline & & $\mathrm{PP}$ & 0 & - & - & & - & - \\
\hline & \multirow[t]{2}{*}{ May } & $\mathrm{PE}$ & 2 & $1.8 \pm 0.5$ & $1.4 \pm 0.9$ & \multirow[t]{2}{*}{$12.5 \pm 0.4$} & No & No \\
\hline & & $\mathrm{PP}$ & 1 & 3.0 & 0.8 & & Yes & No \\
\hline \multirow[t]{4}{*}{2013} & \multirow[t]{2}{*}{ March } & PE & 2 & $1.8 \pm 0.7$ & $1.1 \pm 0.8$ & \multirow[t]{2}{*}{$10.3 \pm 2.8$} & Yes & No \\
\hline & & $\mathrm{PP}$ & 1 & 5.0 & 1.2 & & Yes & yes \\
\hline & \multirow[t]{2}{*}{ April } & PE & 3 & $2.2 \pm 1.1$ & $1.1 \pm 0.6$ & \multirow[t]{2}{*}{$12.4 \pm 1.1$} & Yes & No \\
\hline & & $\mathrm{PP}$ & 0 & - & - & & - & - \\
\hline \multirow[t]{2}{*}{2014} & \multirow[t]{2}{*}{ April } & $\mathrm{PE}$ & 1 & 1.6 & 0.8 & \multirow[t]{2}{*}{$13.3 \pm 1.6$} & No & No \\
\hline & & PP & 0 & - & - & & - & - \\
\hline
\end{tabular}

The mean fish length \pm sd for the month is reported, in accordance with Fig. 2a, and the indication whether the mean value of the fragment length is larger than the mean lumen diameter of the stomach-side and/or anus-side (yes) or not (no). The same evaluation is done considering the aforementioned lumen dimensions increased of $50 \%$ (lumen*1.5) 
Fig. 7 Contribution of the different colours to: a the fibre abundance; $\mathbf{b}$ the fragment abundance. Dark blue and black, coloured red and green, no colour white and transparent
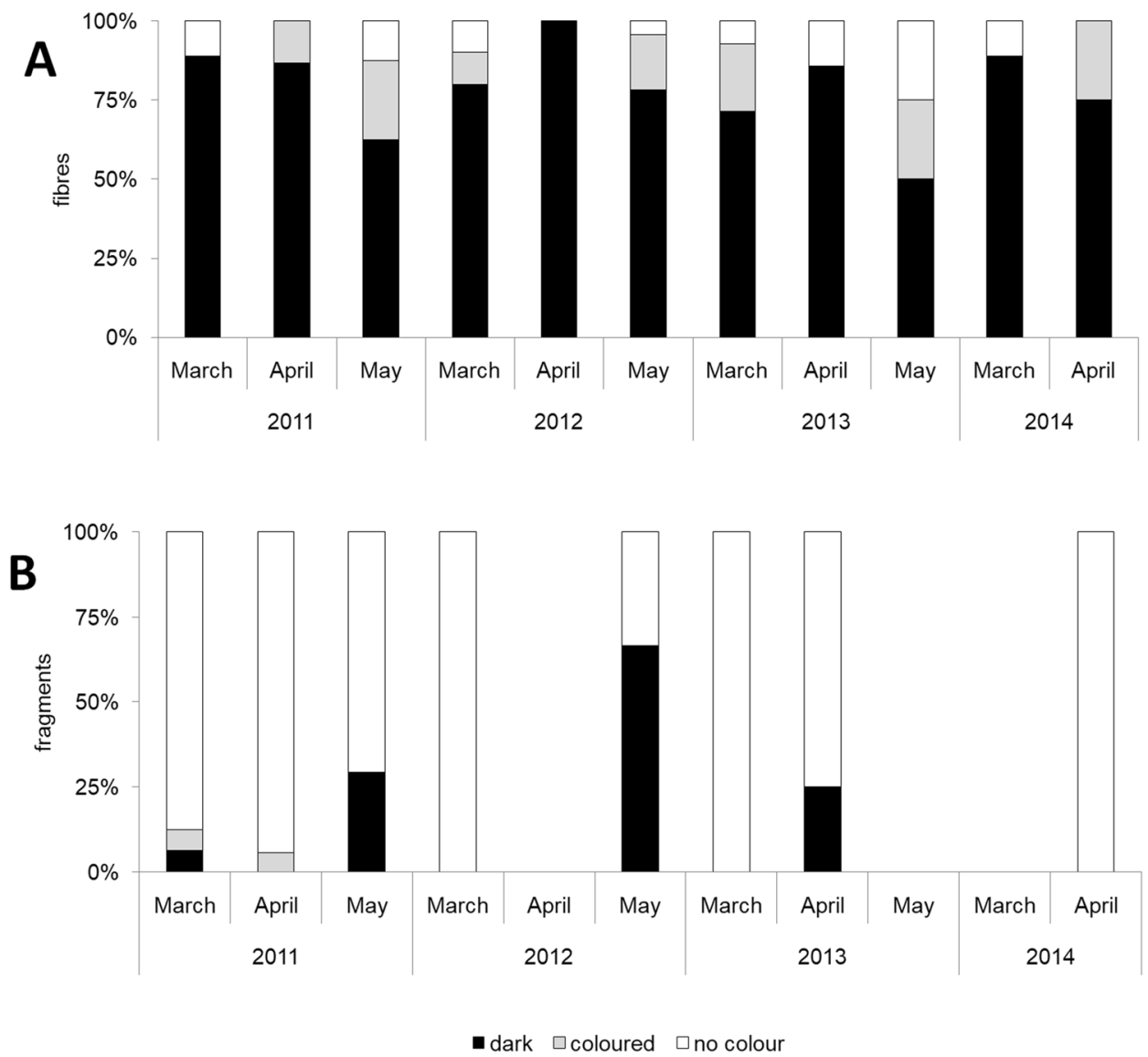

were also found, especially green and red. However, fragments (Fig. 7b) were mainly white or transparent, i.e., not coloured (only one green fragment and a red fragment were found in the 4 years). In 2011, 27\% of fragments were white and $57 \%$ were transparent. In the other years, the number of fragments was low: four in 2012 (0\% white and 50\% transparent), seven in 2013 (29\% white and $57 \%$ transparent), and one white fragment in 2014.

\section{Discussion}

\section{Microparticles in the stomach content}

A continuous feeding activity along the spring period is necessary for anchovies, due to the high-energy demand for fast growth, quick sexual maturation, and gamete production (Bonanno et al. 2016; Compa et al. 2018). In our samples, the statistical analyses related to anchovy characteristics highlighted significant differences between the months, determined mainly by the organism growth and sexual maturation. In this species, the energy demand for reproduction depends on food intake rather than from energy reserves (Somarakis et al. 2004). In particular, females need to feed at a high rate to offset the high-energy costs of egg maturation and serial spawning (James 1987); therefore, they could ingest more microparticles. However, no difference of microparticle abundance in the stomach among females, males, or undetermined specimens was found; the microparticles were found in females as well as the other two groups.

E. encrasicolus perform filter-feeding and particulatefeeding, in this case selecting its prey from the zooplankton community (Van der Lingen et al. 2006; Rumolo et al. 2016). Plastic fragments, especially the transparent ones that have a size range similar to zooplankton (Collignon et al. 2014), may be mistaken for zooplanktonic organisms, (Boerger et al. 2010; de Sá et al. 2015), although some other species prefer dark colours, similar to their common prey (Ory et al. 2018). Copepods have a smooth exoskeleton, often transparent and colourless, similar to plastic fragments or filaments. Nadal et al. (2016) found that bogues, a demersal semipelagic species, misidentify microplastic as potential preys. Visual confusion has been demonstrated in predator fish that have ingested transparent, translucent, or white plastic items similar to gelatinous prey (Choy and Drazen 2013). Erroneous predation on transparent fragments is in agreement with our results, which showed a large dominance of these clean and white fragments over dark or coloured ones. 
Compa et al. (2018) found an inverse relationship between the fibre contents and the Fulton's condition factor for Sardina pilchardus but not for E. encrasicolus. In the Ligurian Sea, the correlation with the anchovy condition factor was significant and positive for fragments, indicating that a dominance of individuals displaying a good ratio between body weight and length (higher Fulton's factor) was positively correlated to a higher ingestion of fragments.

Notwithstanding the difficulties to measure or properly estimate anchovy swimming speed, James and Findlay (1989) and Politikos et al. (2011) suggested a reduction of this speed when anchovies feed by filtration and an increase during bite-predation. More energy can be devoted to feeding activity given that the prey, i.e., zooplankton, is a superior food source (James et al. 1989). The correlation between fragments per individual and the Fulton's condition factor seems in agreement with the previous observations by James and collaborators; namely, more energy may be used for active feeding when fish are in good condition, while when the Fulton's factor is low, an increased energy cost of bite-predation may not be energetically favourable. However, anchovies in poorer condition can likely still increase their swimming speed to perform particle-feeding, as confirmed by the presence of some fragments in the stomach of anchovies of 2012 and 2014, the 2 years showing the lowest mean values of the Fulton's condition factor.

As shown by the significant positive correlations between the fragment content per individual and the gonad weight and GSI, the organisms that ingest fragments were maturing for reproduction. They need extraenergy inputs, such those provided by the predation of zooplanktonic organisms as opposed to filtration of detritus or phytoplanktonic cells (James et al. 1989; Politikos et al. 2011). These anchovies may have mistaken anthropogenic fragments with zooplankton while in search for food and can be more influenced than others by the detrimental effects of anthropogenic microparticles. Whether this possibility could affect the more active reproducers is not known. For the eastern Ligurian Sea, the commercial load of anchovies has recently been characterised by smaller specimens than in the past (Piroddi et al. 2015); ingestion of anthropogenic microparticles could have a role in this decrease together with climatic changes, environmental deterioration, and excessive fishing.

The significant correlation among the stomach-content weight and fibre content per individual suggests that fibres are not selected, but probably filtered passively; a higher the food intake correlates with higher fibre numbers. The presence of coloured and transparent fibres, along with the dominance of dark fibres, indicates a lack of selectivity.

\section{Clearance of microparticles in the stomach- intestine tract}

The information related to the time needed by fishes, and particularly anchovies, to empty their stomach and intestine is scarce (Lusher et al. 2013). Consequently, the time an anthropogenic microparticle remains inside the organism and causes deleterious effects is not fully understood (Jovanović 2017).

Some experiments have shown that some fish egest microplastics after several hours to a couple of days (Grigorakis et al. 2017). For sardine, Van der Lingen (1998) found rates of gastric evacuation $(R)$ ranging from 0.06 to $0.29 \mathrm{~h}^{-1}$ in laboratory experiments, with substantially higher values when the diet was based on diatoms and lower values for zooplankton. Tudela and Palomera (1995) observed that the gastric evacuation rate obtained by Bulgakova (1993) $\left(R=1.05 \mathrm{~h}^{-1}\right)$ was high; therefore, they suggested a rate of $0.423 \pm 0.196 \mathrm{~h}^{-1}$. Studying fishes larger than anchovy, Lambert (1985) observed that adult mackerel (Scomber scombrus) cleared their stomachs of silversides (Menidia menidia) at a constant rate; the time to complete emptying was approximately $28 \mathrm{~h}$ and did not seem to be affected by either ration size or body weight. All of these observations highlight that the retention time for natural and anthropogenic materials in the stomach of pelagic fishes is generally less than a day.

If the microparticle is small enough to pass through the intestinal tract and all of its bottlenecks, the microparticles which we observed were likely ingested few hours to 1 day before, as observed by Jovanović (2017) for microplastics. Similarly, Güven et al. (2017) stated that microplastic occurrence in the gastrointestinal tract of fish is ephemeral. This is relevant, because this process highlights the possibility that the sedimentation of anthropogenic micro-items to the bottom via faecal matter is not sporadic, but continuous, and it may contribute significantly to the disappearance of low-density microplastic from the surface layers of the sea as observed for mesopelagic fishes (Cózar et al. 2014), whose faeces show a significant sedimentation velocity (Robison and Bailey 1981). Fibres and smaller fragments may follow this path without any mechanical damage for the fish, nor for the repletion feeling that may slow or stop the feeding activity (Nadal et al. 2016). However, despite being small, fibres may clump and could be hazardous if they block feeding appendages or the passage of food (Lusher et al. 2013). The presence of only one item in the anchovy stomach could be due to a low concentration of the microparticles in the water coupled with longer residence times. In this case, the potential rate of storing microparticles in the deeper layers via faecal production would be decreased and the chemical threat to anchovies would be increased. Other negative effects may derive from the leaching of toxic substances 
from the particles, such as stains, plastic components, or pollutants adsorbed during the particle residence time in the seawater (Oliveira et al. 2013; Koelmans 2015; Batel et al. 2016; Tanaka and Takada 2016). In our case, the dominance of PE over PP and the absence of other plastic types is a negative signal, because PE more efficiently absorbs hydrophobic chemicals, such as polychlorinated biphenyls (PCBs) (Teuten et al. 2009). In addition, PE is mainly translocated into the livers of clupeid fish species such as E. encrasicolus (Collard et al. 2017), pointing to a threat that is not fully understood. However, the finding of significant concentrations of phthalates in tissues of whales living around the Ligurian Sea (Fossi et al. 2012) indicates that all organisms that exhibit filter-feeding, including anchovies, could be subject to toxicological impact.

Problems arise especially when the particles are larger than the intestine tract. We considered the mean dimension of stomach-side and anus-side tracts for each body length class of anchovies, also assuming that the intestine can expand its lumen when a large particle passes through, but the real extension possibility of the tracts is not known. The plastic microparticles often had acute angles and were hard; therefore, they can damage the intestinal walls during their transit. In our study, a higher quantity of fragments in the anchovy stomach was found in the spring of 2011. Additionally, in 2011, the colours of fragments were mainly transparent (no-colour type, Fig. 7), and in 2012, it showed a higher proportion of dark colours. The higher fragment presence was possibly due to the peculiar meteo-climatic features of that period. A North Atlantic Oscillation index lower than - 1 for the winter of 2010-2011 (https://www.cpc.ncep. noaa.gov) likely increased the inflow of potentially contaminated waters from the northern Tyrrhenian Sea (Astraldi et al. 1999; Baini et al. 2018). However, the higher Fulton's condition factor of 2011 suggests that, besides a potentially higher fragment concentration in the seawater, anchovies in 2011 could have been more efficient in particle-feeding due to their better condition.

In 2011, a large portion of the microplastic fragments showed dimensions larger than the stomach-side tract or the anus-side tract, sometimes falling in the mesoplastic size (4 fragments larger than $5 \mathrm{~mm}$, Barnes et al. 2009). This means that these microparticles could not exit the stomach and, even if they came to the intestinal tract, they could not be ejected. This event could easily occur for the shortest individuals ( $9 \mathrm{~cm}$ long, for instance), which showed stomachside and anus-side lumen significantly smaller than those of the larger organisms; but also the longest anchovies had often a lumen smaller than the fragments found in their stomachs.

Are these microparticles retained indefinitely by the organisms? In our samples, the very low abundance of organisms having more than one fragment in their stomach indicates that anchovies remove these particles easily, or that the concentration of fragments is low, despite that Fossi et al. (2012) and Collignon et al. (2014) identified the western side of our sampling area as a hotspot for surface microplastic. The first arrangement for anchovies to expulse microparticles could be regurgitation, a practice that has been already identified in studies on the stomach content of anchovies of the southern Benguela region (James 1987).

Mechanical fragmentation is one of the main processes that microplastic is subjected to at sea (Cózar et al. 2014). Fragmentation can occur also inside the organisms, where chemical transformations take place. Sometimes, the microplastic fragments which we found inside the stomach of anchovies were likely the product of the breaking of larger pieces. Some pieces, instead, showed irregular, rough, and thin sides, as a result of progressive degradation. However, we cannot define whether these pieces were somehow degraded inside the anchovy or the microplastic was subjected to weathering and mechanical erosion before being eaten. Given that, for instance, PE is degraded following photodegradation and/or chemical degradation (Bonhomme et al. 2003; Wang et al. 2004), these particles were likely eroded before being ingested.

The embedding of plastic items in a biological matrix (mainly lipidic) was observed only in three females longer than $14 \mathrm{~cm}$ and actively reproducing. To include the anthropogenic material in a biological sphere may give some advantages, such as smoothing eventual sharp edges and isolating the allochthonous material from the organism before being ejected, when possible. Therefore, fragmentation and, more rarely, embedding could be two methods to remove large plastic from the stomach and intestine, mixing the anthropogenic material with the faeces.

\section{Conclusions}

In the Ligurian Sea, the European anchovy E. encrasicolus is one of the species that frequently encounters synthetic material; indeed, $30-40 \%$ of the analysed specimens contained fibres or fragments in the stomach content. In our study, no significant differences could be observed among females and males, indicating that the ingestion of anthropogenic microparticles is a common activity. The presence of, generally, only one item in the stomach suggests that the residence time of these items is ephemeral, although some problems can arise when fragments larger than the lumen of the intestine are found. In these cases, the fragment may be retained indefinitely in the stomach, exerting deleterious mechanical effects and eventual toxic effects. However, anchovies can regurgitate, if necessary, the items unsuited for nutrition and, sometimes, hard fragments can break inside the muscular stomach, reaching the appropriate dimensions to 
be ejected. The rare recovery of plastic embedded in a biological matrix, preventing the contact of the microparticle with the organism, suggests that anchovies could use several strategies to protect themselves from the accumulation of ineffective and deleterious microparticles. These methods will be even important, given the rising abundance of anthropogenic debris in the sea.

Acknowledgements We thank L. Viviani for kindly providing the anchovy samples, C. Bottinelli and W. Sgroi for the FT-IR analyses, and M. Chiantore for her help in statistical analyses. This research did not receive any specific grant from funding agencies in the public, commercial, or not-for-profit sectors. We thank the anonymous reviewers and the Associate Editor for their suggestions.

Funding Open access funding provided by Università degli Studi di Genova within the CRUI-CARE Agreement.

Data availability The data supporting the findings of this study are available within the article and its supplementary information files.

\section{Compliance with ethical standards}

Conflicts of interest The authors declare that they have no conflict of interest.

Ethical approval This article does not contain any studies with human participants or animals performed by any of the authors.

Open Access This article is licensed under a Creative Commons Attribution 4.0 International License, which permits use, sharing, adaptation, distribution and reproduction in any medium or format, as long as you give appropriate credit to the original author(s) and the source, provide a link to the Creative Commons licence, and indicate if changes were made. The images or other third party material in this article are included in the article's Creative Commons licence, unless indicated otherwise in a credit line to the material. If material is not included in the article's Creative Commons licence and your intended use is not permitted by statutory regulation or exceeds the permitted use, you will need to obtain permission directly from the copyright holder. To view a copy of this licence, visit http://creativecommons.org/licenses/by/4.0/.

\section{References}

Anastasopoulou A, Mytilineou C, Smith CJ, Papadopoulou KN (2013) Plastic debris ingested by deep-water fish of the Ionian Sea (Eastern Mediterranean). Deep Sea Res Pt 1(74):11-13

Anderson MJ, Gorley RN, Clarke KR (2008) PERMANOVA+ for PRIMER: Guide to software and statistical methods. PRIMERE, Plymouth, UK

Arthur C, Baker J, Bamford H (2009) Effects, and fate of microplastic marine debris. In: Arthur C, Baker J, Bamford H (eds) Proceedings of the international research workshop on the occurrence. NOAA Technical Memorandum NOS-OR\&R-30, Tacoma, NA

Astraldi M, Balopoulos S, Candela J, Font J, Gacic M, Gasparini GP, Manc B, Theochari A, Tintoré J (1999) The role of straits and channels in understanding the characteristics of Mediterranean circulation. Progr Oceanogr 44:65-108
Baini M, Fossi MC, Galli M, Caliani I, Campani T, Finoia MG, Panti C (2018) Abundance and characterization of microplastics in the coastal waters of Tuscany (Italy): the application of the MSFD monitoring protocol in the Mediterranean Sea. Mar Pollut Bull 133:543-552

Bakun A, Agostini VN (2001) Seasonal patterns of wind-induced upwelling/downwelling in the Mediterranean Sea. Sci Mar 65(3):243-257

Barnes DKA, Galgani F, Thompson RC, Barlaz M (2009) Accumulation and fragmentation of plastic debris in global environments. Philos Trans R Soc B Biol Sci 364:1985-1998. https://doi. org/10.1098/rstb.2008.0205

Batel A, Linti F, Scherer M, Erdinger L, Braunbeck T (2016) Transfer of benzo[a] pyrene from microplastics to Artemia nauplii and further to zebrafish via a trophic food web experiment: CYP1A induction and visual tracking of persistent organic pollutants. Environ Toxicol Chem 35:1656-1666

Battaglia P, Pedà C, Musolino S, Esposito V, Andaloro F, Romeo T (2016) Diet and first documented data on plastic ingestion of Trachinotus ovatus L 1758 (Pisces: Carangidae) from the Strait of Messina (central Mediterranean Sea). Ital J Zool 83:121-129. https://doi.org/10.1080/1125000320151114157

Bellas J, Martínez-Armental J, Martínez-Cámara A, Besada V, Martínez-Gómez C (2016) Ingestion of microplastics by demersal fish from the Spanish Atlantic and Mediterranean coasts. Mar Pollut Bull 109:55-60

Boerger CM, Lattin GL, Moore SL, Moore CJ (2010) Plastic ingestion by planktivorous fishes in the North Pacific Central Gyre. Mar Pollut Bull 60:2275-2278

Bonanno A, Barra M, Basilone G, Genovese S, Rumolo P, Goncharov S, Popov S, Nardelli BB, Procaccini G, Aronica S, Patti B, Giacalone G, Ferreri R, Fontana I, Tranchida G, Mangano S, Pulizzi M, Gargano A, di Maria A, Mazzola S (2016) Environmental processes driving anchovy and sardine distribution in a highly variable environment: the role of the coastal structure and riverine input. Fish Oceanogr 25:471-490. https://doi. org/10.1111/fog 12166

Bonhomme S, Cuer A, Delort AM, Lemaire J, Sancelme M, Scott C (2003) Environmental biodegradation of polyethylene. Polym Degrad Stab 81:441-452

Borme D, Tirelli V, Brandt SB, Fonda Umani S, Arneri E (2009) Diet of Engraulis encrasicolus in the northern Adriatic Sea (Mediterranean): ontogenetic changes and feeding selectivity. Mar Ecol Prog Ser 392:193-209

Bulgakova YU (1993) Intensity of feeding of the Black Sea anchovy, Engraulis encrasicolus, during the spawning period. J Ichthyol 32(7):146-151

Cedervall T, Hansson LA, Lard M, Frohm B, Linse S (2012) Food chain transport of nanoparticles affects behaviour and fat metabolism in fish. PLoS ONE 7:e32254

Choy CA, Drazen JC (2013) Plastic for dinner? Observations of frequent debris ingestion by pelagic predatory fishes from the central North Pacific. Mar Ecol: Prog Ser 485:155-163

Claessens M, De Meester S, Van Landuyt L, De Clerck K, Janssen CR (2011) Occurrence and distribution of microplastics in marine sediments along the Belgian coast. Mar Pollut Bull 62:2199-2204

Clarke KR, Gorley RN (2006) PRIMER V6: User manual/tutorial. PRIMER-E Ltd, Plymouth, UK

Cole M, Galloway TS (2015) Ingestion of nanoplastics and microplastics by Pacific oyster larvae. Environ Sci Technol 49:1462514632. https://doi.org/10.1021/acsest5b04099

Collard F, Gilbert B, Compère P, Eppe G, Das K, Jauniaux T, Parmentier E (2017) Microplastics in livers of European anchovies (Engraulis encrasicolus, L). Environ Poll 229:1000-1005 
Collignon A, Hecq J-H, Glagani F, Voisin P, Collard F, Goffart A (2012) Neustonic microplastic and zooplankton in the North Western Mediterranean Sea. Mar Pollut Bulletin 64:861-864

Collignon A, Hecq J-H, Galgani F, Collard F, Goffart A (2014) Annual variation in neustonic micro- and meso-plastic particles and zooplankton in the Bay of Calvi (Mediterranean-Corsica). Mar Pollut Bull 79:293-298. https://doi.org/10.1016/jmarpolbul 201311023

Compa M, Ventero A, Iglesias M, Deudero S (2018) Ingestion of microplastics and natural fibres in Sardina pilchardus (Walbaum 1972) and Engraulis encrasicolus (Linnaeus 1758) along the Spanish Mediterranean coast. Mar Poll Bull 128:89-96

Cózar A, Echevarria F, Gonzalez-Gordillo JI, Irigoien X, Ubeda B., Hernandez-Leon S, Palma AT, Navarro S, Garcia-de-Lomas J, Ruiz A, Fernandez-de-Puelles ML, Duarte CM (2014) Plastic debris in the open ocean. Proc Nat Acad Sci 111:10239-10244

Cubillos L, Claramunt G (2009) Length-structured analysis of the reproductive season of anchovy and common sardine off central southern Chile. Mar Biol 156:1673-1680

Davison P, Asch RG (2011) Plastic ingestion by mesopelagic fishes in the North Pacific Subtropical Gyre. Mar Ecol: Prog Ser 432:173-180

de Sá LC, Lús LG, Guilhermino L (2015) Effects of microplastics on juveniles of the common goby (Pomatoschistus microps): confusion with prey, reduction of the predatory performance and efficiency, and possible influence of developmental conditions. Environ Pollut 196:359-362

Deudero S, Alomar C (2015) Mediterranean marine biodiversity under threat: reviewing influence of marine litter on species. Mar Pollut Bull 98:58-68

Eriksen M, Lebreton LCM, Carson HS, Thiel M, Moore CJ, Borerro JC, Galgani F, Ryan PG, Reisser J, Dam HG (2014) Plastic pollution in the world's oceans: more than 5 trillion plastic pieces weighing over 250,000 tons afloat at sea. PLoS ONE 9:e111913

Estrada M, Vaqué D (2014) Microbial components. The Mediterranean Sea. Springer, Dordrecht, Netherlands, pp 87-111

Fossi MC, Panti C, Guerranti C, Coppola D, Giannetti M, Marsili L, Minutoli R (2012) Are baleen whales exposed to the threat of microplastics? A case study of the Mediterranean fin whale (Balaenoptera physalus). Mar Pollut Bull 64:2374-2379. https://doi. org/10.1016/j.marpolbul.2012.08.013

Fossi MC, Romeo T, Baini M, Panti C, Marsili L, Campani T, Canese S, Galgani F, Druon J-N, Airoldi S, Taddei S, Fattorini M, Brandini C, Lapucci C (2017) Plastic debris occurrence, convergence areas and fin whales feeding ground in the Mediterranean marine protected area Pelagos sanctuary: a modeling approach. Front Mar Sci 4:167. https://doi.org/10.3389/fmars.2017.00167

Froese BR (2006) Cube law condition factor and weight-length relationships: history meta-analysis and recommendations. J Appl Ichthyol 22:241-253. https://doi.org/10.1111/j1439 $-0426.2006 .00805 . x$

Gómez F, Gorsky G (2003) Microplankton annual cycles in the Bay of Villefranche, Ligurian Sea NW Mediterranean. J Plankton Res 25:323-339

Grigorakis S, Mason SA, Drouillard KG (2017) Determination of the gut retention of plastic microbeads and microfibers in goldfish (Carassius auratus). Chemosphere 169:233-238

Güven O, Göokdag K, Jovanović B, Kıdeys AE (2017) Microplastic litter composition of the Turkish territorial waters of the Mediterranean Sea and its occurrence in the gastrointestinal tract of fish. Environ Pollut 223:286-294. https://doi.org/10.1016/jenvp ol201701025

Hidalgo-Ruz V, Gutow L, Thompson RC, Thiel M (2012) Microplastics in the marine environment: a review of the methods used for identification and quantification. Environ Sci Technol 46:3060-3075
James AG (1987) Feeding ecology diet and field-based studies on feeding selectivity of the Cape anchovy Engraulis capensis Gilchrist. South African J Mar Sci 5:673-692. https://doi.org/10.2989/02577 6187784522784

James AG, Findlay KP (1989) Effect of particle size and concentration on feeding behaviour selectivity and rates of food ingestion by the Cape anchovy Engraulis capensis. Mar Ecol: Prog Ser 50:275-294

James AG, Probyn T, Seiderer J (1989) The relationship between respiration rate swimming speed and feeding behaviour in the cape anchovy Engraulis capensis Gilchris. J Exp Mar Biol Ecol 131:81-100

Jovanović B (2017) Potential consequences of fish ingestion of microplastic. Integr Environ Assess Manag 13:510-515

Koelmans AA (2015) Modelling the role of microplastics in bioaccumulation of organic chemicals to marine aquatic organisms, a critical review. In: Bergmann M, Gutow L, Klages M (eds) Marine anthropogenic litter. Springer International Publishing, Cham $(\mathrm{CH})$, pp 309-324

Lacroix GJ, Nezlin NP, Djenidi S (2001) Ecosystem response to the atmospheric forcing in the Southern Ligurian Sea in 1997-1999. Rapp Comm Int Mer Medit 36:72

Ladewig SM, Bao S, Chow AT (2015) Natural fibers: a missing link to chemical pollution dispersion in aquatic environments. Environ Sci Technol 49(21):12609-12610. https://doi.org/10.1021/acses t5b04754

Lamb CF (2001) Gustation and feeding behaviour. In: Houlihan D, Boujard T, Joblin M (eds) Food intake in fish. Blackwell Science, London, pp 108-130

Lambert TC (1985) Gastric emptying time and assimilation efficiency in Atlantic mackerel (Scomber scombrus). Can J Zool 63(4):817-820

Lusher AL, McHugh M, Thompson RC (2013) Occurrence of microplastics in the gastrointestinal tract of pelagic and demersal fish from the English Channel. Mar Pollut Bull 67:94-99

Marty J-C, Chiavérini J, Pizay M-D, Avril B (2002) Seasonal and interannual dynamics of nutrients and phytoplankton pigments in the western Mediterranean Sea at the DYFAMED time series station (1991-1999). Deep-Sea Res Pt II 49:1965-1985

Nadal MA, Alomar C, Deudero S (2016) High levels of microplastic ingestion by the semipelagic fish bogue Boops boops (L) around the Balearic Islands. Environ Pollut 214:517-523

Neves D, Sobral P, Ferreira JL, Pereira T (2015) Ingestion of microplastics by commercial fish off the Portuguese coast. Mar Pollut Bull 101:119-126

Oliveira M, Ribeiro A, Hylland K, Guilhermino L (2013) Single and combined effects of microplastics and pyrene on juveniles $(0 \mathrm{p}$ group) of the common goby Pomatoschistus microps (Teleostei Gobiidae). Ecol Indic 34:641-647

Ory NC, Gallardo C, Lenz M, Thiel M (2018) Capture swallowing and egestion of microplastics by a planktivorous juvenile fish. Environ Pollut 240:566-573

Pedá C, Caccamo L, Fossi MC, Gai F, Andaloro F, Genovese L, Perdichizzi A, Romeo T, Maricchiolo G (2016) Intestinal alterations in European sea bass Dicentrarchus labrax (Linnaeus 1758) exposed to microplastics: preliminary results. Environ Pollut 212:251-256

Piroddi C, Gristina M, Zylich K, Greer K, Ulmanc A, Zeller D, Pauly D (2015) Reconstruction of Italy's marine fisheries removals and fishing capacity, 1950-2010. Fish Res 172:137-147

Politikos DV, Triantafyllou G, Petihakis G, Tsiaras K, Somarakis S, Ito S-I, Megrey BA (2011) Application of a bioenergetics growth model for European anchovy (Engraulis encrasicolus) linked with a lower trophic level ecosystem model. Hydrobiologia 670:141-163

Remy F, Collard F, Gilbert B, Compère P, Eppe G, Lepoint G (2015) When microplastic is not plastic: the ingestion of artificial cellulose fibers by macrofauna living in seagrass macrophytodetritus. 
Environ Sci Technol 49:11158-11166. https://doi.org/10.1021/ acsest5b02005

Rios-Fuster B, Alomar C, Compa M, Guijarro B, Deudero S (2019) Anthropogenic particles ingestion in fish species from two areas of the western Mediterranean Sea. Mar Pollut Bull 144:325-333

Robison BH, Bailey TG (1981) Sinking rates and dissolution of midwater fish fecal matter. Mar Biol 65:135-142

Rochman CM, Tahir A, Williams SL, Baxa DV, Lam R, Miller JT, Teh F-C, Werorilangi S, Teh SJ (2015) Anthropogenic debris in seafood: plastic debris and fibers from textiles in fish and bivalves sold for human consumption. Sci Rep. https://doi.org/10.1038/ srep14340

Romeo T, Pietro B, Pedá C, Consoli P, Andaloro F, Fossi MC (2015) First evidence of presence of plastic debris in stomach of large pelagic fish in the Mediterranean Sea. Mar Pollut Bull 95:358-361

Rumolo P, Bonanno A, Barra M, Fanelli E, Calabrò M, Genovese S, Ferreri R, Mazzola S, Basilone G (2016) Spatial variations in feeding habits and trophic levels of two small pelagic fish species in the central Mediterranean Sea. Mar Environ Res 115:65-77

Siokou-Frangou I, Christaki U, Mazzocchi MG, Montresor M, Ribera d'Alcalá M, Vaqué D, Zingone A (2010) Plankton in the open Mediterranean Sea: a review. Biogeosciences 7:1543-1586

Somarakis S, Palomera I, Garcia A, Quintanilla L, Koutsikopoulos C, Andrés U, Motos L (2004) Daily egg production of anchovy in European waters. ICES J Mar Sci 61:944-958

Suaria G, Avio CG, Mineo A, Lattin GL, Magaldi MG, Belmonte G, Moore CJ, Regoli F, Aliani S (2016) The Mediterranean Plastic Soup: synthetic polymers in Mediterranean surface waters. Sci Rep 6(1):37551

Tanaka K, Takada H (2016) Microplastic fragments and microbeads in digestive tracts of planktivorous fish from urban coastal waters. Sci Rep 6:34351

Teuten EL, Saquing JM, Knappe DR, Barlaz MA, Jonsson S, Björn A, Rowland SJ, Thompson RC, Galloway TS, Yamashita R, Ochi D,
Watanuki Y, Moore C, Viet PH, Tana TS, Prudente M, Boonyatumanond R, Zakaria MP, Akkhavong K, Ogata Y, Hirai H, Iwasa S, Mizukawa K, Hagino Y, Imamura A, Saha M, Takada H (2009) Transport and release of chemicals from plastics to the environment and to wildlife. Philos Trans R Soc Lond Ser B Biol Sci 364:2027-2045

Van der Lingen CD (1998) Gastric evacuation, feeding periodicity and daily ration of sardine Sardinops sagax in the southern Benguela upwelling ecosystem. S Afr J Mar Sci 19:305-316. https://doi. org/10.2989/025776198784126791

Van der Lingen CD, Hutchings L, Field JG (2006) Comparative trophodynamics of anchovy Engraulis encrasicolus and sardine Sardinops sagax in the southern Benguela: are species alternations between small pelagic fish trophodynamically mediated? Afr J Mar Sci 28:465-477

van Sebille E, Wilcox C, Lebreton L, Maximenko N, Hardesty BD, van Franeker JA, Eriksen M, Siegel D, Galgani F, Law KL (2015) A global inventory of small floating plastic debris. Environ Res Lett 10:124006. https://doi.org/10.1088/1748-9326/10/12/124006

Wang YZ, Yang KK, Wang XL, Zhou Q, Zheng CY, Chen ZF (2004) Agricultural application and environmental degradation of photo-biodegradable polyethylene mulching films. J Poly Environ $12: 7-10$

Wright S, Thompson R, Galloway T (2013) The physical impacts of microplastics on marine organisms: a review. Environ Pollut 178:483-492

Zuur AF, Ieno EN, Smith GM (2007) Analysing ecological data. Springer, New York, p 648

Publisher's Note Springer Nature remains neutral with regard to jurisdictional claims in published maps and institutional affiliations. 